\title{
IMPORTÂNCIA ESTRATÉGICA DA ÁGUA PARA O TERCEIRO MILÊNIO
}

\author{
FLÁVIO GOMES DE ALMEIDA*1 \\ Universidade Federal Fluminense \\ P. BORGES ${ }^{* *}$ \\ Escola de Aperfeiçoamento de Oficiais do Exército \\ D. CHAGAS ${ }^{* * *}$ \\ Universidade Federal Fluminense/Veterinária \\ M. A. S. QUEIRÓZ ${ }^{* * * *}$ \\ Cirurgiã Dentista \\ C. E. 8. SANTOS S $^{* * * * *}$ \\ Secretaria Municipal de Meio Ambiente do Rio de Janeiro \\ C. M. M. R. SILVA***** \\ Fundação Municipal de Educação de Niterói
}

\section{INTRODUÇÃO}

Segundo Jonh E Kennedy, "quem for capaz de resolver os problemas da água será merecedor de dois prêmios Nobel, um pela paz e outro pela ciência". Sem água não há vida. Ela está presente não só na constituição física dos animais como em todas as ações humanas: produção de energia, alimentação, transporte, integração, turismo... Desde a antigüidade, observa-se que o acesso à água é fonte de poder e ao mesmo tempo ponto de conflito de interesses.

Os Recursos Humanos constituem fundamento predominante da expressão econômica, por ser o Homem, agente essencial da produção e do consumo, é não só o organizador e executor do processo produtivo, mas também seu beneficiário (ESG, 1998). Porém ressaltasse-se ainda no mesmo fundamento doutrinário, que o ambiente é o condicionante mais geral de todos os fenômenos relativos à pessoa, à sociedade e à própria vida, sendo que uma das grandes responsabilidades do Homem é manter o equilíbrio em sentido amplo. Esta manutenção consiste, essencialmente, em conciliar as transformações que ele vai produzindo com a preservação dos ecossistemas, principalmente os aquáticos, base essencial de sustentabilidade da vida. A missão do homem deve ser a do aprimoramento da vida, bem como a vigência dos valores, de modo que a vida não se tome autodestrutiva ou infeliz.

A água estará em foco neste novo milênio já aparecendo, com freqüência, nos noticiários. Notícias sobre poluição, falta da água, seca e, mais recentemente, o problema da geração de energia têm sido muito veiculadas.

A verdade é que sempre se pensou a água como um bem abundante e, por conseqüência,

\footnotetext{
$1 *$ Geógrafo

* * Militar (T. CeI.)

* *** Médico veterinário

* *** Cirurgiã Dentista

$* \quad * * * *$ Engenheiro Florestal

$* \quad * * * * *$ Professora
} 
inesgotável. Mas trata-se de uma falsa impressão. Da totalidade da água que temos em nosso planeta, 97,5\% é salgada, o que exigiria enormes investimentos para viabilizar o seu consumo e mesmo sua utilização como insumo para o processo produtivo. Os $2,5 \%$ restantes são água doce, mas cerca de $2 / 3$ se encontra em forma de geleiras, de modo que somente 0,78 se encontra disponibilizada para o consumo, mas parte dela está poluída(RJ, 2002).

Além disso a população mundial aumenta, sendo crescente também seus níveis de urbanização e industrialização, o que aumenta a demanda de água, cuja quantidade tem se mantido constante ao longo dos últimos séculos. Assim, a deficiência em qualidade e quantidade de recursos hídricos tornou-se evidente e preocupante.

A água não se encontra distribuída de forma homogênea em nosso planeta, bem como sua demanda é também heterogênea, fato este que torna necessária uma eficiente gestão, de maneira que se contemple o uso múltiplo dos recursos hídricos, com a água estando disponível em quantidade e qualidade suficientes para os interessados, pois ela é um bem natural público, logo é de todos, sendo obrigação do Estado fornecer água em quantidade e qualidade para todos os segmentos da sociedade, não somente os que pagam ou que pagarão por ela. Ninguém pode cobrar pelo que não é seu, principalmente o Estado, a não ser que seja para exportação e que traga retorno em qualidade de vida à sociedade.

A água é também o recurso natural mais importante para o crescimento econômico e social da população, de forma que ela é hoje o mais importante vetor para a indução ao investimento em determinadas regiões, sendo hoje um diferencial competitivo essencial para esta ou aquela área.

O presente trabalho tenta desenvolver a idéia de que as questões ambientais, principalmente no caso da água, envolvem conflitos extra, inter e intra-espécies, por alimento, espaço/disponibilidade e pela reprodução, seja dentro da natureza — intocada pela "Civilização Humana" -, seja nas sociedades ditas civilizadas. Aqui estamos interessados em estudar conflitos e suas correlações junto à gestão dos recursos hídricos. E quando se estudam conflitos humanos, sociais, logo surgem as idéias de Justiça e Direito. Aliá Maas (1962) já ressaltava como prérequisitos para a Gestão, no caso apenas recursos hídricos, a existência do Estado de Direito em sua sociedade democrática.

Nas questões de uso do recurso hídrico, ocorrem conflitos de interesses e de interpretações, face às expectativas, significados e classificações diferentes dos recursos naturais. No palco da discussão sobre a qualidade do ambiente social e natural contracenam os atores sociais, tendo como cenário os conceitos jurídicos e não jurídicos, como o desenvolvimento sustentável e a água. Neste palco de luzes e sombras, todos nós somos atores sociais desempenhando diversos papéis, às vezes sem conhecer o roteiro da estória apenas torcendo por um final feliz (SÉGUIN, 1999).

As vantagens do meio ambiente equilibrado são recebidas e percebidas de maneira generalizada pela comunidade local e pelos que estão distantes dos acontecimentos. No palco social, onde estas questões se desenrolam, alguns atores desconhecem seus verdadeiros papéis. Além da grande platéia passiva e silenciosa, os atores principais interagem basicamente dentro da relação contida no binômio: Estado/sociedade civil organizada.

Como figurantes nesta peça, mas recitando texto que pode mudar o desfecho da estória, temos os cientistas e os ativistas políticos. A grande e passiva platéia é o planeta. Estes atores se propõem a interagir na arena da conservação/preservação das águas no planeta. Os formadores de opinião, dentro da dicotomia opinião pública e opinião que se publica, ganham paulatinamente espaço e importância no rumo das decisões globais (SÉGUIN,1999).

No caso específico brasileiro, não devemos permitir que as decisões ditas globais, venham a interferir no nosso rumo e destino. É discutível a idéia da escassez em nosso país, mas não quer dizer que com isso possamos admitir o desperdício, pois sabemos do compromisso que se tem com as gerações futuras. Os subsídios promovidos pelo governo brasileiro, em tempos passados, aos pecuaristas, embora contribuíssem para a prosperidade econômica do setor, provocou enorme desmatamento das matas protetoras de nossos mananciais hídricos, e reforçou a concentração fundiária nas mãos de grupos privilegiados.

A introdução de sistema de monocultura permitiu o aumento dos ganhos dos exportadores. Entretanto, eles modificaram os sistemas produtivos tradicionais, as cadeias alimentares em 
nossos rios através do uso de agrotóxicos, provocando migrações para as cidades e expulsando algumas populações rurais para zonas agrícolas menos produtivas e mais sensíveis do ponto de vista da conservação dos solos e da água.

Esse fenômeno, freqüentemente, gera desarticulação das estruturas sociais e aumento das pressões sobre o meio ambiente e conflitos. Lembramos que um sistema social, para ser considerado coeso, deve atender, de acordo com Ribeiro \& Vargas:

- A satisfação das necessidades individuais;

- O controle do processo de mudança social pelos indivíduos e coletividades;

- A igualdade de oportunidades;

- A igualdade de direitos(acesso aos recursos naturais, à informação e aos bens e serviços);

- Paz e justiça social;

- Pleno emprego;

- A distribuição eqüitativa de das rendas e dos custos;

(RIBEIRO e VARGAS, LADA)

A grande pergunta que se coloca como ponto de reflexão no presente trabalho, já que estamos tratando de um país muito pouco coeso em seu sistema social, projetando determinados cenários, é a seguinte: haverá uso social da água no Brasil e no Mundo no terceiro milênio, sem que hajam conflitos? E quais os tipos de conflitos que já ocorrem ou que poderão ocorrer?

\section{AVALIAÇÃO DA PROBLEMÁTICA}

Através da história da água percebemos que esta se constitui enquanto fonte de poder desde a antigüidade. Quantos conflitos gerou entre fazendeiros, cidades, e até países?

Sendo um elemento natural, porém finito, a água é fonte de cobiça dos menos favorecidos pela natureza. A oferta ainda supera a demanda. No entanto, os estudiosos prevêem, em longo prazo, problemas graves de escassez desse bem.

$\mathrm{O}$ homem interfere na natureza desviando rios, criando grandes lagos, desmatando as florestas, destruindo montanhas, criando grandes túneis subterrâneos, poluindo, cimentando terrenos, asfaltando as margens dos rios, permitindo o crescimento desordenado das cidades...

O crescimento desordenado provocando a ocupação do solo por loteamentos clandestinos ou não - mas "consentidos" pelas autoridades - em áreas adjacentes à mananciais que se constituem em reservatórios para o abastecimento, presente e futuro, dos habitantes da região, é em parte responsável pela poluição das águas desses mananciais.

Analisando o fator urbanização, nos grandes aglomerados urbanos, não é a população que impacta diretamente o meio, mas atividades engendradas pelo setor produtivo, que atraindo a população sobre ele despeja toda sorte de dejetos: o ar poluído pelas indústrias, os rios usados como via de esgotos domiciliares e industriais, a erosão de terrenos íngremes, a exploração imobiliária.

Vale salientar que os problemas ambientais ocorridos em uma região impactam não só o território local, como outros sítios próximos.

Como exemplo para o conflito hídrico entre cidades recorremos ao caso do Pólo Industrial de Cubatão. De um lado temos as questões técnicas e econômicas relacionadas ao abastecimento público e industrial, geração de energia elétrica originando receita, a manutenção de um sistema concebido para gerar energia elétrica, com represamento e reversões artificiais exigindo elevados custos para sua manutenção, e, de outro lado, as questões ambientais e de qualidade de vida junto às comunidades beneficiárias das águas ribeirinhas, que não necessariamente precisam estar próximas à represa.

Concebida para trabalhar com grande quantidade de água a redução do seu uso, ameaçou a operação do Pólo, e, por conseguinte, a população que dele dependia economicamente. Este fator, aliado ao alto grau de poluição instaurado mobilizou a opinião pública em relação ao uso da água e à busca de soluções que, sem inviabilizar o Pólo, revitalizassem a potencialidade da água.

Quando analisamos a variabilidade ao longo do país, especificamente neste caso, a região do Pólo de Cubatão, observamos que, onde existe maior demanda, a água não está disponível, seja 
na quantidade ou na qualidade, gerando conflitos ocasionados pelo desequilíbrio entre a oferta e a demanda nos usos múltiplos da água.

Em situações de conflito, lembramos que a prioridade no uso da água é para o homem e depois para a dessedentação de animais. Como o fator econômico é prioridade e "detém" o poder que lhe é auferido pelo dinheiro, faz-se necessária a regulamentação através de agências reguladoras que envolvam a sociedade como um todo em seu gerenciamento.

Uma das soluções encontradas pelo governo para tentar resolver o problema foi a criação do Comitê da Bacia Hidrográfica da Baixada Santista, onde se percebe uma acirrada disputa pelo uso da representatividade nesse Comitê.

\section{Exame da Dinâmica e Estudo da Tendência}

Um dos elementos chave do planejamento de recursos hídricos é a análise prospectiva da evolução das necessidades de água dos diferentes setores de atividade, no quadro do desenvolvimento sócio-econômico nacional e regional e do ordenamento do território, em horizontes temporais relativamente alargados. Porém, deverá entender-se, a este respeito, que as realidades futuras são o resultado de interações complexas de variáveis, algumas delas controláveis, mas, outras não. Na verdade, o planejamento é um instrumento dinâmico no domínio dos recursos hídricos onde as incertezas são especialmente relevantes e não podem deixar de ser consideradas de forma explícita. Estas incertezas, desde cedo presentes nos fenômenos hidrológicos e nas leis e métodos estatísticos que permitem a sua avaliação, são insuperáveis na formulação dos cenários sócio-econômicos que influem na utilização da água. De fato, as utilizações da água influenciam e são influenciadas por fatores de caráter mais ou menos permanente à escala da vida humana (climáticos, geomorfológicos e biofísicos) e outros de natureza profundamente dinâmica como são os sócio-econômicos e demográficos.

A última década veio introduzir um dinamismo suplementar às realidades sócio-econômicas, fazendo surgir um conceito novo que as influencia: a globalização. A complexidade do mercado, a realização de alianças, parcerias econômicas, um serviço tecnológico em permanente evolução posto ao dispor do desenvolvimento, da inovação, da produção e da redução do tempo de vida dos produtos são, afinal, os vetores fundamentais pelos quais deverão ser pautados os exercícios prospectivos. Não obstante partir de pressupostos de grande abrangência temática, pretendeu-se uma prospectiva socioeconômica profundamente direcionada sobre os fatores que importa considerar em planejamento de recursos hídricos e que designadamente influenciam as necessidades de água e o grau de modificação dos sistemas hídricos que decorrem das atividades humanas (artificialização dos meios hídricos, geração de resíduos). Considerou-se, por isso, os seguintes agrupamentos de uso da água: uso urbano (que incluem o uso doméstico), industrial, agrícola, turístico e de produção de energia.

Assim, na prospectiva socioeconômica tornou-se necessário estimar variáveis fundamentais relacionadas com o produto das atividades econômicas, evolução demográfica e outros elementos dinâmicos.

\section{Análise dos elementos dinâmicos}

\section{Crescimento da população}

Desde 1900, a quantidade de água doce utilizada no mundo multiplicou-se por quatro, enquanto a população apenas duplicava. Caso a tendência não se altere, a quantidade de água doce disponível per capita por ano, cairá dos atuais $6.800 \mathrm{~m}^{3}$ para $4.800 \mathrm{~m}$ em 2025 . Este cálculo teórico da UNESCO baseia-se no volume de toda água que corre nos rios, diminuída dos efeitos da evaporação e das infiltrações, ignorando, portanto, as quantidades mínimas de água necessárias para manter vivos os ecossistemas aquáticos e as águas de difícil acesso. 
O censo do IBGE, nos últimos seis anos, apontou um crescimento da população brasileira de 7,5\%; mostrou que a renda média brasileira subiu $25 \%$; que $20 \%$ das residências não têm água tratada e $40 \%$ não dispõem de esgoto. Tudo isso no rastro de tendências delineadas a partir da década de 50, como: a urbanização acelerada, o aumento da idade média da população e a redução da taxa de crescimento demográfico.

$\mathrm{O}$ batimento entre os parágrafos acima indica uma demanda crescente de água para o futuro, sobretudo a tratada para contato direto com o organismo humano. A crescente concentração da população em cidades gera a necessidade de captação de grandes volumes de água para a geração de insumo, como água tratada, energia, alimentação e lazer. Acarreta, ainda, uma grande produção de efluentes a ser tratada por empresas de saneamento público ou privado.

\section{Crescimento desordenado das cidades}

O crescimento desordenado das cidades brasileiras é um perigo muito maior ao bem estar comum da população, consumindo uma gama cada vez maior de recursos públicos das prefeituras, do que o crescimento demográfico.

A promessa de melhora da condição de vida nas grandes cidades produziu uma migração de pessoas de pouca qualificação e com pouca perspectiva de um razoável posicionamento no mercado de trabalho. Mal remunerado, este contingente humano concentra-se nas periferias das cidades, nos morros, mangues e margens de cursos d'água. Qualquer que seja a opção de concentração que o grupo faça, essa ocupação será danosa. No caso dos morros, os aglomerados humanos, lá instalados, causam o desmatamento das encostas e o conseqüente assoreamento dos cursos d'água pela terra trazida para os seus leitos pelas chuvas e pelo lixo gerado pelo quotidiano das pessoas.

Outro aspecto dessa ocupação é a necessidade de investimentos, cada vez mais altos, para levar os serviços básicos aos seus cidadãos, como a água, cujos reservatórios normalmente encontram-se em um nível inferior ao destes consumidores: energia, telefonia, escolas, etc.. Em outros casos, de uma forma geral, as concentrações humanas se fazem próximas a mananciais d'água, sejam rios, córregos, manguezais ou lagos, normalmente poluindo-os e assoreando-os.

A tendência para o futuro é o aumento destes agrupamentos humanos, baixando a qualidade de vida das cidades brasileiras. Isto, impinge maiores gastos aos cofres públicos para saneamento e prestação de serviços, além de prejudicar o bem estar comum pelas deficiências sanitárias existentes nestes guetos, tornando-se pólos de proliferação de doenças. É importante ressaltar o provável aumento das enchentes, pela obstrução dos cursos d'água, retirada da cobertura vegetal e aumento das áreas impermeabilizadas; deslizamentos de encostas e encarecimento da captação, tratamento e distribuição da água.

\section{Saúde e saneamento}

Os dados do Ministério da Saúde demonstram que de $80 \%$ a $90 \%$ das internações hospitalares, no Brasil, são decorrentes de doenças transmitidas por água contaminada como: cólera, esquistossomose, febre tifóide, tracoma e diarréia. Cada $\mathrm{R} \$ 1,00$ aplicado em saneamento básico representa de $\mathrm{R} \$ 4,00$ a $\mathrm{R} \$ 5,00$ economizados em saúde. O déficit brasileiro, por investimentos em saneamento, é de R $\$ 40$ bilhões (OMS).

Voltando-se aos tópicos anteriores e agregando o fato de que poucos investimentos estão sendo feitos em saneamento, a projeção para o futuro é de que os gastos com saúde devam aumentar na mesma medida do déficit público em saneamento. Verifica-se uma queda da qualidade de vida e probabilidade de proliferação de endemias e epidemias.

\section{Desperdício}


Da água tratada e distribuída no Brasil para consumo humano, $50 \%$ é perdida em alguma parte do processo de tratamento e distribuição, ou é desperdiçada pelo consumidor final.

A solução para a equação apresentada acima, é a educação da população. Educação esta que deve ser conduzida nas escolas, através da conscientização da necessidade de preservação desse bem natural. E também uma forma de esclarecer que a água tratada é um direito de todos. Para o Estado é uma solução simples e barata.

No levantamento das tendências, a observação dos itens já tratados, agregada ao fato de que as campanhas para redução do desperdício de água são bastante acanhadas, pressupõe que haverá um aumento da perda de água por descuido no uso do recurso pela população. Pode-se prever que no futuro algumas cidades brasileiras serão obrigadas a racionar o fornecimento de água.

\section{Redução das matas riparias}

O desmatamento e ocupação desordenada do solo, seja nas cidades ou no campo, vem gerando uma redução das matas riparias. Ainda que protegidas por lei, a falta de fiscalização e ganância de empreendedores imobiliários e agricultores, está levando à destruição da proteção dos cursos d'água, aumentando a exposição dos espelhos d'água ao Sol. Tal fato, além da perda imediata de água pelo aumento da evaporação, permite que as enxurradas, geradas pelas chuvas, levem uma maior quantidade de terra e sedimentos para o leito dos cursos d'água, assoreando-os.

Ainda que as campanhas do governo tenham minimizado o desmatamento de tal vegetação, a falta de reposição da flora perdida e a utilização das margens dos rios para plantio, pecuária e empreendimentos imobiliários contribuem para o agravamento da situação.

Embora não esteja ligado à destruição de matas riparias, o garimpo por lavra já é responsável pelo aterramento de rios e destruição de microssistemas no Centro-Oeste e Amazônia. Fato que, a continuar com a precária fiscalização atual, gerará a perda de outras fontes de recursos hídricos para o futuro.

\section{Reservatórios}

Dos reservatórios d'água existentes no mundo responsáveis pelo abastecimento de água potável, pela irrigação de lavouras e pela produção de energia elétrica, muitos correm o risco de perder sua capacidade por causa da sedimentação de lama. Caso não se adotem medidas urgentes, um quinto da capacidade dessas barragens poderá ser perdida ao longo das próximas décadas, trazendo problemas ao abastecimento no futuro. Segundo alguns especialistas, essa perda poderá ser ainda maior se a questão do clima no mundo piorar e se continuar o desmatamento em áreas estratégicas. Com o aquecimento do clima global, a tendência é haver mais tempestades e inundações, acelerando os níveis naturais de erosão em torno dos rios que alimentam os reservatórios. Trazendo o problema para a realidade brasileira, pode-se aliar aos fenômenos já citados o crescimento desordenado das cidades, a falta de educação da população que joga seu lixo nos cursos d'água e o longo tempo que o país levou sem investimentos substanciais nesta área, significando dizer que parte da capacidade de armazenamento dos reservatórios brasileiros já foi perdida.

Para o futuro observa-se um agravamento da situação face ao já exposto nesta análise de tendências e a redução dos investimentos na construção de barragens.

\section{Agricultura}

A agricultura é, de longe, a maior consumidora de água doce, sobretudo devido ao desenvolvimento da irrigação. Atualmente, é responsável por cerca de dois terços do consumo total, proporção que só muito levemente deverá declinar até 2025. Portanto, qualquer redução do consumo passa pela melhoria das técnicas de irrigação. Em Israel e países com pouca 
disponibilidade hídrica a técnica de irrigação por gotejamento é empregada com considerável redução do consumo d'água.

Observa-se que no futuro haverá uma competição cada vez mais acirrada entre os diversos consumidores de recursos hídricos - campo e cidade - tanto pelo crescimento exagerado desta última quanto pela necessidade de mais bocas a alimentar pelo primeiro.

\section{Turismo e lazer}

Os postais e propagandas de lugares turísticos, que mais influenciam e despertam nos cidadãos o desejo de visitá-los, têm em sua composição harmônica algum espelho d' água, seja marinho, fluvial, lacustre ou composição destes. Essa forma de marketing demonstra a simpatia e atração do ser humano pela água.

No Brasil, seguindo a tendência mundial proliferam os parques do tipo Waterplay como: o Beach Park, em Fortaleza e Wet'n Wild, na Barra da Tijuca, no Rio de Janeiro e muitos outros, sendo um segmento em expansão dentro da indústria de entretenimento. Ainda nessa ótica, junto às barragens, lagos e orla marítima é cada vez maior o desenvolvimento de atividades do esporte aquático e de lazer.

A indústria do turismo gera bilhões de dólares por ano sendo a que mais cresce no mundo. Aliada à de entretenimento, demonstra uma crescente demanda da civilização ocidental por lazer.

Espelhos d' água são ainda fontes inspiradoras para os empreendedores imobiliários, que usam a água como agregado na valorização dos seus produtos.

Para o futuro há de se supor um acentuado aumento da demanda por lazer e os mananciais hídricos serão peças indispensáveis nessa exploração desses dois segmentos

\section{Energia}

O sistema brasileiro gerador de energia elétrica apresenta características que o tornam único no cenário mundial. Seja pelo seu porte, uma vez que cobre um país de dimensões continentais, seja pela predominância da fonte hidrelétrica, contribuindo com cerca de $95 \%$ da geração total, seja, ainda, pelo expressivo intercâmbio de energia entre suas regiões, como verdadeiras transposições de rios.

Embora exista uma tendência do crescimento do parque gerador térmico, com destaque para a iniciativa privada, é imperioso um aproveitamento mais intenso das disponibilidades hidrelétricas do País, haja vista a situação experimentada nos últimos meses de restrição forçada do consumo de energia elétrica, associada ao fato de tratar-se de um insumo renovável, destacando-se ainda que apenas $25 \%$ do potencial hídrico conhecido, de $260 \mathrm{GW}$, encontra-se aproveitado.

O crescimento do consumo anual do Brasil é da ordem de 4,5\%, obrigando o crescimento da geração da mesma, nessas proporções. Porém a falta de investimento, nas últimas décadas, gerou um déficit de oferta que criou o descompasso do apagão. Até recentemente, a iniciativa do governo em abrir o setor aos investimentos privados, sem regulamentação mais apurada e a obrigatoriedade de seguir o inventário das bacias, criou a possibilidade do uso não otimizado do recurso.

A projeção a longo prazo indica que o Estado está procurando o gerenciamento dos recursos hídricos nacional de forma mais responsável na medida em que segue o Plano Nacional de Águas (PNA), estabelece para as bacias, já inventariadas, que sejam seguidas as projeções de exploração do recurso. Para as não inventariadas estão sendo feitos convênios para a sua realização. $\mathrm{O}$ programa de incentivo às Pequenas Centrais Elétricas $(\mathrm{PCH})$ está proporcionando o fornecimento de energia a empresas e pequenas comunidades não atendidas pelo sistema nacional de distribuição. Contudo, a necessidade de investimentos pesados do Estado ou da iniciativa privada faz-se necessária para a recuperação do período de estiagem dos investimentos e o afastamento dos brasileiros da possibilidade de novos racionamentos. 


\section{Desertificação}

Desertificação é um processo de degradação ambiental por ação antrópica, nas regiões áridas, semi-áridas e subúmidas secas, com aumento gradativo da pobreza. Entende-se como degradação ambiental, a degradação do solo, da flora, da fauna e dos recursos hídricos.

A desertificação é um dos mais graves problemas tanto em função da área abrangida como pela população atingida, que sofre com o aumento da pobreza, como efeito da degradação de suas terras.

As ações nacionais, implementadas no âmbito do Ministério do Meio Ambiente, tiveram seu desenvolvimento atrelado ao acordo internacional firmado com o Programa das Nações Unidas para o Desenvolvimento Sustentável — PNUD, assinado em 1995, BRA 93/036. Nessa data, iniciou-se um esforço de sensibilização interna no Ministério no sentido de envolver todas as secretarias, assim como, sensibilizar os demais órgãos, para a elaboração da Política Nacional e do Plano Nacional de Combate à Desertificação. Foram estabelecidas parcerias com ONGs para possibilitar um trabalho efetivo em lugares afetados pelo processo. Procurou-se agregar ações visando o fortalecimento institucional do ponto focal.

Contudo, mesmo havendo um envolvimento institucional de várias vocações, seja de governo, ONGs, universidades, institutos, etc., desde o início das discussões do referido tema, ainda assim, não existe uma política abrangente para, o combate à desertificação e mitigação dos efeitos da seca. Assim, com os resultados obtidos e considerando o estágio atual de implementação da Convenção, existe a necessidade de novas estratégias, como: coordenar as ações de controle da desertificação com as ações de combate aos efeitos da seca; priorizar a análise econômica dos impactos da desertificação na economia, no ambiente (solos, água, biodiversidade) e na sociedade; e orientar os órgãos atuantes na região segundo preceitos da CCD.

\section{Conflitos}

Do Danúbio ao Nilo, os grandes rios freqüentemente serviram de trunfo durante a Guerra Fria. Hoje, o Egito e a Etiópia, como todas as repúblicas da Ásia Central, procuram negociar, para sua vantagem mútua, a gestão dos rios, irrigação e barragens. Simples estudos preliminares, relativos a rios ou a lençóis freáticos, permitem à Namíbia e a Botsuana, à Índia e ao Bangladesh superarem suas desconfianças. A diplomacia da água não realiza milagres, mas favorece colaborações inéditas entre juristas, técnicos e populações diretamente interessadas. Juntos, eles buscam os meios de partilhar o mais vital de todos os nossos recursos. É importante ressaltar que a humanidade percebeu que, no aspecto água, não haverá vantagens entre os contendores e sim a distribuição de perdas, da miséria e dos prejuízos econômicos. Não existe amizades no conserto das nações mas, a constatação de que, no tocante a este recurso, o único caminho plausível é a cooperação.

\section{Arcabouço jurídico}

A Constituição Federal de 1988 modificou, em vários aspectos, o texto do Código de Águas, de 1934. Uma das alterações feitas foi preconizar que todas as águas do Brasil são do domínio público. Houve, assim, extinção do domínio privado da água subterrânea, previsto no Art. 96 do Código das Águas de 1934.

Por sua vez, a Lei Federal n. ${ }^{0}$ 9.433, de 08 de janeiro de 1997, instituiu a Política Nacional de Recursos Hídricos, criou o Sistema Nacional de Gerenciamento de Recursos Hídricos, regulamentou o inciso XIX do art. 21 da Constituição Federal de 1988, e alterou o art. $1^{\circ}$ da Lei n. ${ }^{\circ} 8.001$, de 13 de março de 1990, que modificou a Lei n. ${ }^{\circ} 7.990$, de 28 de dezembro de 1989 .

Ressalta-se que a Lei n. ${ }^{\circ}$ 9.433/97 estabeleceu novos tipos de organização para a gestão compartilhada do uso da água. 
Finalmente, a Lei n. ${ }^{\circ}$ 9.984, 17 de julho de 2000, criou a Agência Nacional de Águas ANA, para implementar a Política Nacional de Recursos Hídricos, cuja formulação ficará a cargo da Secretaria Nacional de Recursos Hídricos — SRH, do Ministério do Meio Ambiente MMA.

Neste quadro, todavia, embora a Lei 9.433/97 fale de gestão integrada da bacia hidrográfica, as ações até agora implantadas têm contemplado, tão somente, as águas que fluem pelos rios, as acumuladas nos açudes e nos pantanais.

Da mesma forma, falta uma legislação específica que estabeleça os princípios a serem observados para captação das águas de chuva e de reuso das águas pluviais ou tratadas e injetadas no subsolo em cada uma das UGRHI.

\section{ELABORAÇÃO DOS CENÁRIOS}

$\mathrm{Na}$ elaboração dos cenários da situação da água no Brasil para o futuro, alguns aspectos deverão ser observados, tais como:

— a curto prazo, de cinco a dez anos, não são consideradas quaisquer reflexos para o sistema, pelo simples fato de serem insignificantes;

- a médio prazo, de dez a vinte anos, as implicações e alterações do quadro são influenciadas por medidas já tomadas ou realizações recentes;

- a longo prazo, a partir dos vinte anos, os reflexos serão sentidos pelo impacto decorrente das discussões ora em pauta, desde que implementadas a curto prazo.

\section{Cenário A}

O primeiro cenário que se coloca diante do país, no que toca à gestão dos recursos hídricos, é o de manutenção do curso atual dos acontecimentos, sem a definição de titularidade entre as esferas do poder quanto ao órgão concedente nos casos de colisão de jurisdição; poucos investimentos, sob a alegação de falta de recursos e financiamentos; legislação específica quanto ao reuso das águas; programas de esclarecimento da população quanto as formas de evitar o desperdício do recurso e evitar a poluição dos recursos hídricos.

Acreditar que a sociedade organizada é capaz de suprir as deficiências decorrentes da omissão do Poder público, é assumir a premissa de que esse tipo de conduta teria evitado o apagão, é julgar que cabe à sociedade decidir os investimentos do governo, quando tem, na verdade, apenas a capacidade de propor alternativas e assessorar as decisões. Se cabe à sociedade conduzir todo o processo, para que um Estado pesado e oneroso?

$\mathrm{O}$ aumento da população do país, o crescimento desordenado das cidades, a necessidade crescente de mais alimentos, a ampliação das áreas afetadas pela desertificação e pela poluição, aliados à inércia dos poderes da república brasileira, suposto neste cenário, gerará a longo prazo um colapso generalizado no gerenciamento dos recurso hídricos. É de se esperar pelo racionamento de luz e água pela incapacidade de geração desses bens de consumo. Espera-se ainda, contrariando a tendência, conflitos generalizados devido à escassez e a falta de um interlocutor competente para solucionar o impasse. Provavelmente a sociedade encontrará uma forma de contornar o problema, contudo, os custos econômicos e sociais serão elevadíssimos.

\section{Cenário B}

A sociedade brasileira e sobretudo o Poder público estão sensibilizando-se para a problemática da gestão adequada e competente dos recursos hídricos nacionais. Nessa perspectiva, a aplicação severa das leis e a implementação das políticas ora discutidas os óbices supra apresentados poderão ser superados a médio e a longo prazo. O Estado não pode se furtar às suas responsabilidades para com a sociedade. 
O retomo da realização dos inventários das bacias para as estatais, que detêm o Know-How, indica o interesse em tornar isento o processo e utilizar otimizadamente o potencial de cada curso d'água.

As políticas de utilização dos recursos estão sendo definidas, ora corrigindo-se deficiências de legislações ultrapassadas, ora regulando aspectos oriundos da evolução tecnológica do homem.

A educação da população quanto à necessidade de conservação e utilização dos recursos hídricos com parcimônia, aliada à conscientização de que a água é finita, trará ao país uma condição melhor de vida e o conseqüente desenvolvimento.

Nesta linha de raciocínio, à luz de atitudes do governo e da sociedade, acredita-se que os óbices, apresentados na análise anterior, poderão ser superados a longo prazo. Sendo necessário, no caso da despoluição de alguns ecossistemas, a ampliação dos prazos estimados. Portanto, o país terá condições de superar-se e apresentar-se mais competitivo e respeitado no cenário mundial.

\section{CONSIDERAÇÕES FINAIS}

Nos aspectos legais, o Brasil está contemplado com excelente legislação ambiental de elevado conteúdo técnico e social. Em relação à água, a Lei Federal n 9433, de 08 de janeiro de 1997, instituiu a Política Nacional de Recurso Hídricos, criou o Sistema Nacional de Gerenciamento de Recursos Hídricos e a tendência é que com a outorga, a quantidade e qualidade da água fiquem asseguradas a todos, pois estamos vislumbrando que o objetivo maior é o BEM COMUM.

Mas em relação ao tratamento de esgoto e ao reuso desta água, a Política para o saneamento básico no Brasil não atende às necessidades da população. Para cada dólar que o governo investe em saneamento básico, quatro são economizados em internações hospitalares decorrentes das moléstias provocadas pela falta de redes de água e esgoto. É necessário acabar com a política de se tratar da doença substituindo-a pela de se cuidar da saúde.

É recomendável uma política que estabeleça prioridades sobre o uso da água, uma vez satisfeitas as necessidades da população. Esta irá decidir qual a atividade econômica mais importante, fazer um planejamento para implementação desta atividade e se a atividade escolhida for muito impactante, se estará disposta a arcar com o ônus ambiental. A população local também deverá otimizar a utilização da água e seu reuso quando for o caso.

Efetivação da reforma agrária fixando o homem ao campo, qualificando-o para atividades inerentes a sua vocação e passando ensinamentos de técnicas conservacionistas do solo e da água através dos extensionistas rurais.

Recomenda-se como estratégia a adoção de ações imediatas no sentido de proteger os recursos hídricos e o desenvolvimento de programas baseados no conceito do uso eficiente da água.

Em situações onde a degradação ambiental é muito acentuada há a necessidade de intervenção humana para a recondução do processo de sucessão florestal.

No que diz respeito à utilização de agrotóxicos, adotar medidas alternativas para diminuir ou mesmo substituir a utilização deste elemento, quer seja através da rotação de cultura, diversificação de produtos agrícolas ou controle biológico entre outras alternativas.

Nas cidades, a implantação de programas de despoluição dos mananciais hídricos, quer sejam de água doce ou salgada. Educação ambiental nas escolas e incentivos ao planejamento familiar para que assim o desejar.

Finalmente, devemos traçar na nossa Política de Gestão dos Recursos Hídricos os seguintes objetivos:

1) De uma maneira mais geral, o de assegurar que a água, recurso natural estratégico para o III milênio, seja posto a serviço dos interesses do país visando o Bem comum, a fim de que seu uso social se dê de forma harmônica e eficiente.

2) De uma forma mais específica, entendemos que cuidar a fim de que os objetivos estabelecidos pela classe dominante, em nome do bem estar do povo, não estejam distanciados dos interesses destes.

3) Administrar as tensões oriundas de conflitos relativos à utilização dos recursos hídricos a 
fim de estabelecer a paz social, valorizando as potencialidades advindas desse recurso beneficiando cada um, bem como a totalidade dos homens.

4) Adequar o uso do potencial hídrico em território brasileiro ao crescimento econômico sem aceitar intervenções consideradas atentatórias à soberania nacional.

Como objetivos de governo ressaltamos:

1) Garantir, através de amparo legal, o uso das reservas hídricas do território nacional.

2) Estabelecer sistema de cobrança de multas para quem poluir rios, lagos, mar.

3) Promover e identificar as potencialidades hídricas do país.

4) Promover a gestão deste bem finito e frágil - a água - com a participação da sociedade , dos técnicos e dos responsáveis pelo governo.

Resumo: O presente trabalho tenta desenvolver a idéia de que as questões ambientais, principalmente no caso da água, envolvem conflitos extra, inter e intra-espécies, por alimento, espaço/disponibilidade e pela reprodução, seja dentro da natureza — intocada pela "Civilização Humana" -, seja nas sociedades ditas civilizadas. Aqui estamos interessados em estudar o prováveis cenários para à Gestão dos Recursos Hídricos no Brasil bem como propor alguns objetivos que deverão estar inseridos na Política Nacional de Gerenciamento dos Recursos Hídricos.

Palavras Chaves: Recursos Hídricos, Gestão, Cenários

Abstract: Present work try to develop the idea that environmental questions, specially about water, involve conflicts extra, inter and intra species; by food, space/availability, and their reproduction, inside nature — preserved from Human Civilization — or among civilized societies. Here we are interested to study probable scenery in the management of Brazilian Hydrous Resources, and to propose some objectives that will be inserted into National Politics on Hydrous Resources management.

Key-word: Hidrous resources, environmental, territorial management

\section{BIBLIOGRAFIA}

ALMEIDA, D.S.; DUARTE, A.J.; ARAÚJO, R.P. 2000. Projeto de Recuperação de Matas Ciliares e Nascentes da Bacia do Rio dos Mangues - Porto Seguro, Bahia. In: Anais do $6^{\circ}$ Congresso de Exposição Internacional sobre Florestas - FOREST. Porto Seguro, Bahia. p. 575.

BANCO MUNDIAL .1990. Capim vetiver: a barreira vegetal contra a erosão. Banco Mundial, Washington, D.C., pp. 78 pág.

DUBOIS J.C.L., (1994). 1992. Uma alternativa silvipastoril para região serrana no Estado do Rio de Janeiro. REBRAF, Rio de Janeiro. Informativo Agroflorestal, .6 (4): 6-7

ESG, 1998. Fundamentos Doutrinários da Escola Superior de Guerra. - Rio de Janeiro: A Escola, 258p

ESTADO DO RIO DE JANEIRO 2002. Recursos Hídrico do Estado do Rio de Janeiro. Legislação Básica.

GUERRA, A. J. T.\& CUNHA, S. B. 1999. Avaliação e Perícia Ambiental/ Sandra Batista da Cunha, Antônio José Teixeira Guerra (orgs). Rio de Janeiro; Bertrand Brasil, 266p.

HELENA, S. 2000. Módulo de Avaliação de Impacto Ambiental do curso de Gestão Ambiental Empresarial. UFF/CT/LATEC.

IBGE, Manual Técnico de Vegetação Brasileira. Rio de Janeiro.

MAAS, H. et al. 1962. Design of Water-Resource Systems, Cambridge, Mass., EUA, Harvard University Press, 1962

POLÍTICA Nacional de Recursos Hídricos - 2002. Legislação Básica, da Secretaria de Recursos Hídricos, do Ministério do Meio Ambiente - Brasília.

RIBEIRO\&VARGAS. 2001. Novos Instrumentos de Gestão Ambiental Urbana/ Helena Ribeiro, Heliana Comin Vargas (orgs.). - São Paulo: Editora da Universidade de São Paulo.

SÉGUIN, Elida. 1999. Lei dos Crimes ambientais. Rio de Janeiro: Ed. Esplanada, 256p

STARZYNSKI, R.; SOARES, P.V.; CARVALHO, J.L. 2002. Relação entre os componentes ambientais e suas implicações na utilização de recursos naturais. In: Curso de Recursos

Hídricos: Produção, Conservação e Recuperação. Cunha, SP.p.2-13. 1999.

ESG, 2002 Pensamento Estratégico da Escola Superior de Guerra.

ESG, Método de Planejamento Estratégico da Escola Superior de Guerra. 
MMA, Água, o desafio para o próximo milênio, da Secretaria de Recursos Hídricos, do Ministério do Meio Ambiente (Anais do seminário para discussão dos anteprojetos de lei para criação da ANA e do SNGRH). 